\title{
The Effects of Orexin A and B on Two Forms of Immobility Responses and on Analgesia
}

\author{
Abraham Miranda-Páez ${ }^{\mathrm{a}, *}$, Priscila Vázquez-León ${ }^{\mathrm{a}}$, Lucía Martínez-Mota $^{\mathrm{b}}$, \\ Vicente Sandoval-Herrera $^{a}$, Ivan Villanueva-Becerril ${ }^{\mathrm{a}}$ and Sergio R. Zamudio ${ }^{\mathrm{a}}$ \\ ${ }^{a}$ Departamento de Fisiología, Escuela Nacional de Ciencias Biológicas, Instituto Politécnico Nacional, Wilfrido \\ Massieu esq. Manuel Stampa s/n Col. Nueva Industrial Vallejo Del. Gustavo A. Madero, México City, Mexico \\ ${ }^{\mathrm{b}}$ Laboratorio de Farmacología Conductual, Dirección de Investigaciones en Neurociencias, Instituto Nacional de \\ Psiquiatría “Ramón de la Fuente Muñiz”, Calzada México-Xochimilco101 Col.San Lorenzo Huipulco, Tlalpan, \\ Mexico City, Mexico
}

\begin{abstract}
The orexins are important for the regulation of several behavioral patterns, including feeding, arousal state, drug seeking, voluntary locomotion and nociception.

Two orexins (A and B), and two different orexin receptors are known, which have differential distribution. This suggests that orexins and distinct orexin receptors may regulate specific behaviors such as immobility associated analgesia. The periaqueductal gray (PAG) is considered to be the main center for the analgesia and immobility responses in the central nervous system (CNS).

Here we compared the effect of orexin A (OX-A) and orexin B (OX-B) after intracerebroventricular (ICV) or the ventrolateral periaqueductal gray (vl-PAG) injection. Two forms of immobility responses were studied: cataleptic (CAT) and tonic (TI) responses. The latter was associated with analgesia as part of a defensive response in several species.

We observed that OX-A was more effective than OX-B to reduce CAT; OX-B was slightly more potent than OX-A to decrease TI and neither orexins were able to induce analgesia when orexins were injected ICV.

After microinjection into vl-PAG CAT was unaffected by orexins and both orexins significantly decrease TI. Microinjected OX-A did not show analgesic activity but OX-B produced significant analgesic effect assessed by tail-flick test.
\end{abstract}

Keywords: Orexins, cataleptic immobility, tonic immobility, analgesia

\section{INTRODUCTION}

Most studies in vivo carried out to assess activity of orexins (also called hypocretins) have utilized direct administration of OX-A into the brain. After intracerebroventricular (ICV) injection, OX-A activates neurons in a pattern consistent with the distribution of orexin peptide and their receptors [1]. OX-B is less popular as an in vivo tool, probably because it is con-

\footnotetext{
*Correspondence to: Abraham Miranda-Páez, Departamento de Fisiología, Escuela Nacional de Ciencias Biológicas, Instituto Politécnico Nacional, Wilfrido Massieu esq. Manuel Stampa s/n Col. Nueva Industrial Vallejo CP:07738 Del. Gustavo A. Madero, México City, Mexico. Tel.: +52 555729 6000/Ext. 52340; E-mail: abmipa@hotmail.com.
}

sidered to be more metabolically labile than OX-A [2], mainly when administered systemically.

Orexin receptors are widely distributed in the CNS. However orexin receptor 1 (OXR1) prevail in: prefrontal cortex and limbic structures, hippocampus, thalamus, ventromedial hypothalamic nucleus, dorsal raphe nucleus, locus coeruleus, spinal cord and dorsal root ganglia, whereas orexin receptor 2 (OXR2) are prominent in cerebral cortex, septal nuclei, hippocampus, medial thalamic groups, hypothalamus and spinal cord $[3,4]$.

Two types of orexin receptors differ in their affinities for the orexins, the G-protein cascades coupled to them, and their expression patterns, so that it has been suggested that they may have different physiological 
roles $[4,5]$. Interestingly both orexin receptors are present in periaqueductal gray (PAG) [5].

On the other hand, there are many ways of immobility response also called behavioral arrest occurring in nature at different contexts with its own phylogeny and ontogeny, which combination results practically unique to each species, but wide spread across animal kingdom [6, 7]. All these forms of immobility share one feature: a neural activated stop of voluntary movements, except those related to breathing.

The cataleptic immobility or catalepsy (CAT) can be defined as a failure to correct externally imposed "awkward postures" [8], or as an immobility in which there are varying degrees of enhanced muscular rigidity and "waxy flexibility" to sustain an awkward or unusual posture [7].

Tonic immobility (TI) is a reversible state of immobility which can be caused by a wide range of external stimuli, in laboratory means physical restraint and releases the animal generally in supine position. Also is conceptualized as innate passive defensive terminal behavior [9] in several species and characterized by a profound and temporary state of motor inhibition.

At present prevailing reports show that activation of orexinergic system leads to increase locomotion and reduce any kind of immobility, which may include certainly CAT and TI. Many of the non-ingestive effects of orexin administration are identical to the cluster of active defensive responses mediated via the lateral and dorsolateral columns of the midbrain PAG, i.e., somatomotor activation, vigilance, tachycardia, hypertension and non-opioid analgesia [10]. On the other hand, activation of ventrolateral PAG (vl-PAG) neurons produces immobility and antinociception [11]. Stimulation of the ventrolateral column of the caudal region of PAG causes powerful antinociceptive effects accompanied by many vegetative phenomena which may include: hypotension, bradycardia, vasodilatation in the muscles of the extremities and a type of immobility known as "hyporeactive" (because there is a noticeable lack of reactions by the animal to any stimulus-be it physical or in its vicinity) $[12,13]$. Such elicited-immobility is indistinguishable from TI.

However are very little published findings related to the effects of orexins on immobility response at different CNS levels and particularly into vl-PAG.

On the other hand several lines of evidence suggest a role for the orexinergic system in nociceptive processing $[14,15]$. Moreover, it has been shown analgesic effect of orexins, mainly for OX-A in several rodent models by different routes of administration and tests, however it is less tested the analgesic effect for OX-B.

\section{MATERIALS AND METHODS}

\section{Animals and housing}

Twenty-four male adult Wistar rats weighing 250-300 g were used; obtained from vivarium of department of Physiology of National School of Biological Sciences. The experimental protocol for the study was approved by the National School of Biological Sciences Ethics and Biosecurity Committee and is in accordance with guidelines established by the National Institute of Health Guide for the Care and Use of Laboratory Animals in 1996, and with those established by The Guide for the Care and Use of Laboratory Animals of the Mexican Council for Animal Care (NOM-062-ZOO-1999). Every effort was made to alleviate any pain or distress that might be experienced by animals during this experiment. We used minimum number of animals required to attain the goals of this study. Behavioral testing always took place between 1000 and 1600 .

\section{Surgical procedures}

Under anesthesia with sodium pentobarbital (Pisabental ${ }^{\circledR}$ Pisa Mexico) (34 mg/kg of body weight i.p.), stainless steel guide canulae (23 gauge $\times 3.5$ or 23 gauge $\times 7 \mathrm{~mm}$ aimed to right lateral ventricle (RLV) $(n=12)$ or vl-PAG respectively $(n=12))$ rats were implanted by stereotaxic surgery (lab standard stereotaxic instrument; World Precision Instruments ${ }^{\circledR}$ Sarasota, Fl, U.S.A.) in RLV (AP: $-1.2 \mathrm{~mm}$; L: $1.2 \mathrm{~mm}$ and DV: $3.5 \mathrm{~mm}$ ) or in right side of vl-PAG (AP: $-7.5 \mathrm{~mm}$; L: $0.5 \mathrm{~mm}$ and DV: $7.0 \mathrm{~mm}$ with $15^{\circ}$ angle) from bregma, middle line and skull respectively according to Paxinos and Watson [16]. The guide cannula was held in place on skull with two screws and dental acrylic glue. A stylet was inserted into the guide cannula and rats were returned to their individual cages for 1 week before behavioral testing in a temperature $\left(24 \pm 1^{\circ} \mathrm{C}\right)$, light $(12: 12$ light cycle, light on at 0700) controlled room and with free access to food and water.

\section{Microinjections}

Animals were injected through the cannula with 0.1 , 0.5 or $1 \mathrm{nmol} / 1 \mu \mathrm{L}$ of OX-A or OX-B (both from Sigma Chemicals ${ }^{\circledR}$ ), or their respective vehicle (VEH sterile isotonic saline solution, $\mathrm{pH}$ 7.4) in a volume of $1 \mu \mathrm{L}$ during 1 minute plus 1 minute to avoid reflux. OX$\mathrm{A}, \mathrm{OX}-\mathrm{B}$ or $\mathrm{VEH}$ were microinjected via an injection 
cannula (30-gauge $\times 10 \mathrm{~mm})$ that extended $1 \mathrm{~mm}$ beyond the tip of guide cannula. The injection cannula was connected to a $1-\mu \mathrm{L}$ syringe (Hamilton Co., Reno, NV, USA) with TYGON microbore tubing (ID: $0.25 \mathrm{~mm}$; OD:0.76 mm) filled with sterile water.

\section{Behavioral testing}

Two minutes after microinjection, the animals were tested for induction of CAT, TI and tail-flick (TF) in the same animal in random order with three minutes intertrial interval. Each animal received one dose of respective orexin (A or B) or $\mathrm{VEH}$ at day of testing; however, animals were microinjected only one dose $(0.0,0.1,0.5$ or $1 \mathrm{nmol})$ for testing randomly with three days between microinjections. Each animal received then four microinjections and three behavioral assessments, resulting in twelve observations for animal. All experiments were videotaped for further revision. There is no interaction found at the order in performed behavioral tests to explain our results, neither some effect attributed to experimental handling.

\section{Immobility testing}

\section{Cataleptic immobility}

The animal was gently pinched on scruff of the neck for approximately $5 \mathrm{~s}$ by using thumb, index and middle fingers, then the rat was placed on two horizontal parallel metal bars device $(1 \mathrm{~cm}$ diameter, $15 \mathrm{~cm}$ length) the lower one up $40 \mathrm{~cm}$ from the surface and the higher one $10 \mathrm{~cm}$ above. The forelimbs were supported on one bar generally the superior, and the hind limbs on another. The subject was released gently into this posture, and the time it remained there before removing one limb off the bars was recorded or until $180 \mathrm{~s}$ had elapsed. This testing was adapted for rat from Fregoso-Aguilar and Zamudio [17].

\section{Tonic immobility}

TI was elicited by clamping the neck, two clamps (5 cm-alligator clips with rubber-coated tips) were applied one in the dorsal and one in the ventral part of the neck, each clamp exerting $1300 \mathrm{~g} / \mathrm{cm}^{2}$ of force on approximately $1 \mathrm{~cm}^{2}$ of the neck skin. The animal is then inverted to a supine-lateral position and gently maintained this posture until stop struggling (if applicable) and keeps immobile. Duration was measured from the time the experimenter's hand was removed until animal recovered the prone position, with maximum of $180 \mathrm{~s}$ [18].

\section{Tail-flick test}

The TF was performed using a Tail-Flick Test Meter (Columbus Instruments ${ }^{\circledR}$, Columbus $\mathrm{OH}$ ), by measuring the latency of the evasive response when applying a heating light beam stimulus to the tail approximately $5 \mathrm{~cm}$ from the base. The light beam turned off at $15 \mathrm{~s}$ as maximum latency to avoid unnecessary tissue damage [13]. The application of thermal radiation to the tail of an animal provokes the withdrawal of the tail by a brief vigorous movement. The advantages of this method are its simplicity and small variability between animals in reaction time measurements under a given set of controlled conditions [13]. A lengthening of the reaction time is interpreted as an analgesic response.

\section{Histological procedures}

After behavioral experiments concluded, animals were overdosed with sodium pentobarbital $(90 \mathrm{mg} / \mathrm{kg}$, i.p.) and perfused intracardially with $0.9 \%$ saline solution followed by $4 \%$ formaldehyde. Their brains were removed manually and stored for at least $48 \mathrm{~h}$ in $10 \%$ formalin. Coronal sections $100-\mu \mathrm{m}$ thick were obtained using a vibroslice $(752 \mathrm{M}$, Cambden Instrument ${ }^{\circledR}$, Lafayette, IN, USA), stained with cresyl violet and mounted with resinous medium $\left(\right.$ Permount ${ }^{\circledR}$ ). Under a light microscope (SMZ-10A, Nikon ${ }^{\circledR}$ Instruments Inc., Melville, NY, USA), the microinjection sites were located with reference to [16]. Only results of behavioral observations from rats in which microinjections sites were within RLV or vl-PAG were used.

\section{Statistical analysis}

Data were compared by repeated measures analysis of variance (RM-ANOVA) tests followed by StudentNewman-Keuls pos-hoc method if necessary to make multiple pairwise-group comparisons. The level of significance was set at $P<0.05$. All analyses were performed using the software Sigma Plot ${ }^{\circledR}$ version 11.1 (Systat Software Inc., San Jose CA, USA).

\section{RESULTS}

Microinjection sites of orexins in the PAG were demonstrated in Fig. 1. Comparing results between different routes of microinjection and among concentration for both orexins the RM-ANOVA showed significant differences $\left(\mathrm{F}_{7,22}=10.518 ; P<0.001\right)$, we found the OX-A decreased duration time of CAT in a 


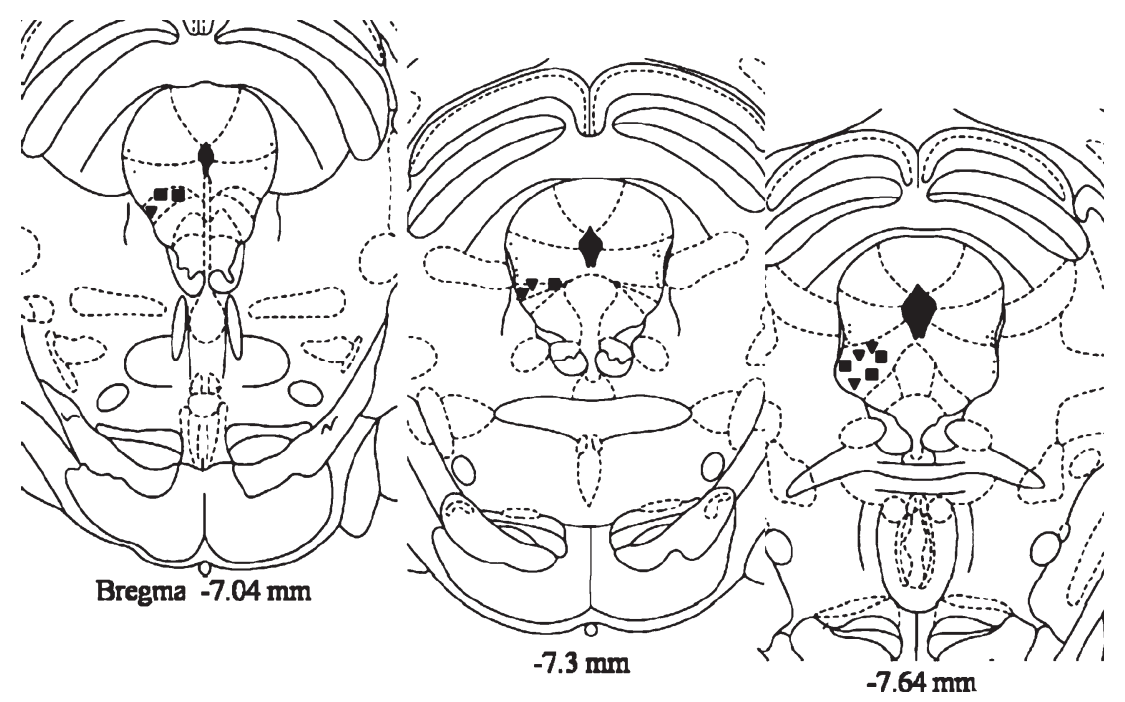

Fig. 1. Scheme of microinjection sites in coronal sections of rat brain (from Paxinos and Watson, 1986). Distances from bregma are indicated (in $\mathrm{mm}$ ). Triangles correspond to microinjections of OX-A; and squares to OX-B.

dose dependent manner when was microinjected ICV (0.1, 0.5 and $1 \mathrm{nmol})$, pos-hoc analysis established that higher concentration of OX-A microinjected ICV result in lower CAT duration compared with VEH, while OX-B decreased the duration of CAT compared with VEH only at concentration of $1 \mathrm{nmol}$ microinjected ICV (Student-Newman-Keuls test, $P<0.05$ ). There was no significant difference when OX-A or OXB were microinjected in vl-PAG compared with VEH (RM-ANOVA: $\mathrm{F}_{7,23}=0.497 ; P=0.827$ ) (Fig. 2).

Regard to TI, we found significant decreased duration when both orexins microinjected ICV (RMANOVA: $\left.\mathrm{F}_{7,28}=5.161 ; P<0.001\right)$, OX-A reduced TI duration only at concentration of $1 \mathrm{nmol}$, while OX-B at 0.5 and $1 \mathrm{nmol}$ decreases duration of TI compared with VEH (pos-hoc Student-Newman-Keuls test, $P<0.05)$. When microinjected in vl-PAG, OXA or OX-B significantly decreased duration of TI at all concentrations tested (RM-ANOVA: $\mathrm{F}_{7,23}=8.184$; $P<0.001$; pos-hoc Student-Newman-Keuls test, $P<0.05$ ) (Fig. 3).

Both orexins microinjected ICV at all concentrations did not affect tail-flick latency (RM-ANOVA: $\left.\mathrm{F}_{7,34}=0.611 ; P=0.743\right)$. Neither OX-A at all concentrations assayed into vl-PAG, however OX-B produced a statistically significant increase (RMANOVA: $\left.\mathrm{F}_{7,22}=7.514 ; P<0.001\right)$ in tail-flick latency at all concentrations microinjected into vl-PAG

\section{CAT DURATION}
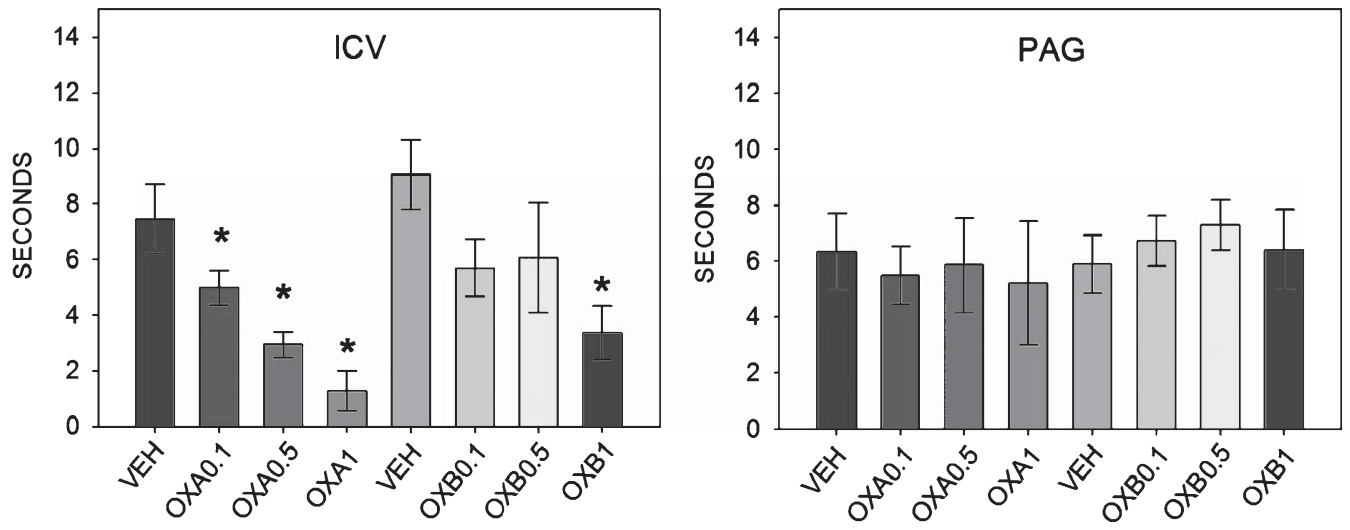

Fig. 2. Mean+SEM of duration time in seconds of CAT in rats microinjected with OX-A, OX-B $(0.1,0.5$ and $1 \mathrm{nmol})$ or VEH, ICV or into vl-PAG. All microinjections were in a volume of $1 \mu \mathrm{L} .{ }^{*} P<0.05$ compared to respective VEH (Student-Newman-Keuls pos-hoc procedure). 
TIDURATION
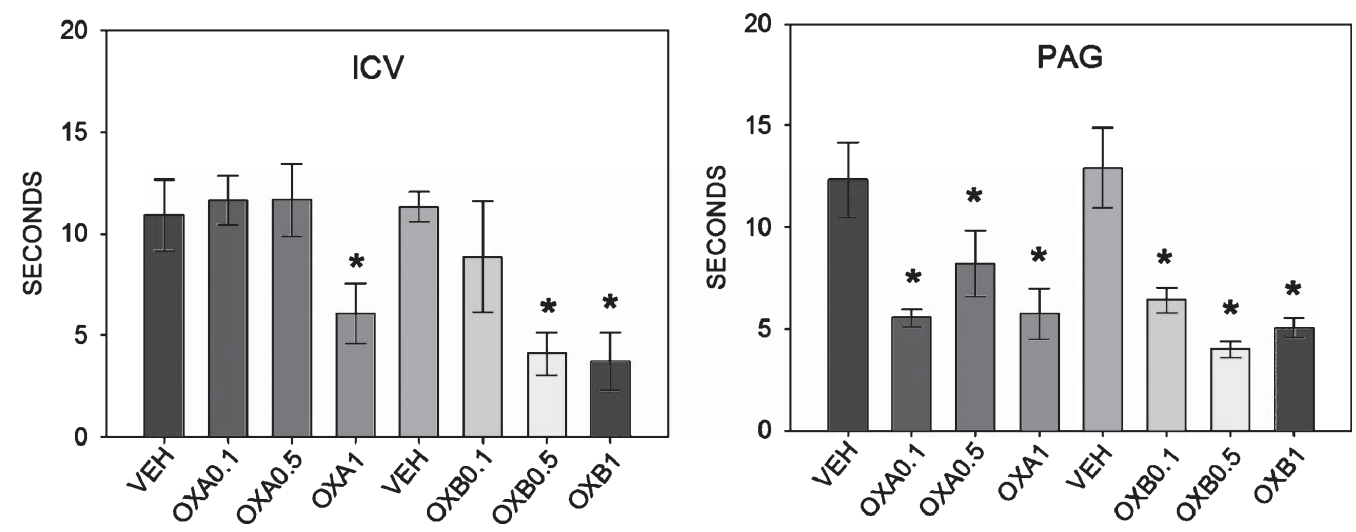

Fig. 3. Mean+SEM of duration time in seconds of TI in rats microinjected with OX-A, OX-B (0.1, 0.5 and $1 \mathrm{nmol})$ or VEH, ICV or into vl-PAG. All microinjections were in a volume of $1 \mu \mathrm{L} .{ }^{*} P<0.05$ compared to VEH (Student-Newman-Keuls pos-hoc procedure).

compared with all concentrations microinjected of OXA and VEH (pos-hoc Student-Newman-Keuls test, $P<0.05)$ (Fig. 4).

\section{DISCUSSION}

Different forms of immobility response could be modulated differentially by orexins. Cataleptic immobility and a form of tonic immobility performed by clamping the neck can be elicited in naive adult rats, and these reactions can be selectively modified by several chemical mediators either systemic or locally in certain nuclei in the CNS. Although experimental differences to develop CAT and TI are obvious, both share some features among which the most important is the inhibition of voluntary movement. Moreover cat- aplexy (otherwise specific immobility accompanying to narcolepsy disorder in nature and thought to be the intrusion of short REM-sleep into the waking state, usually triggered by an emotional experience) has been proposed as an atavistic expression of TI [19]. The hypocretin neurons may directly suppress brain areas involved in the initiation of TI, or act as a stabilizing system on brainstem areas responsible for motor inhibition. The hypocretin system is an alluring candidate for regulation of TI [19].

Likely CAT imply a reaction related to immobility during REM-sleep episodes and be mediated mainly by orexins in centers as hypothalamus [20], locus coeruleus [21], nucleus magnocellularis and pontine inhibitory area [22]. Meanwhile TI represent a way of immobility as passive defensive response

TF LATENCY
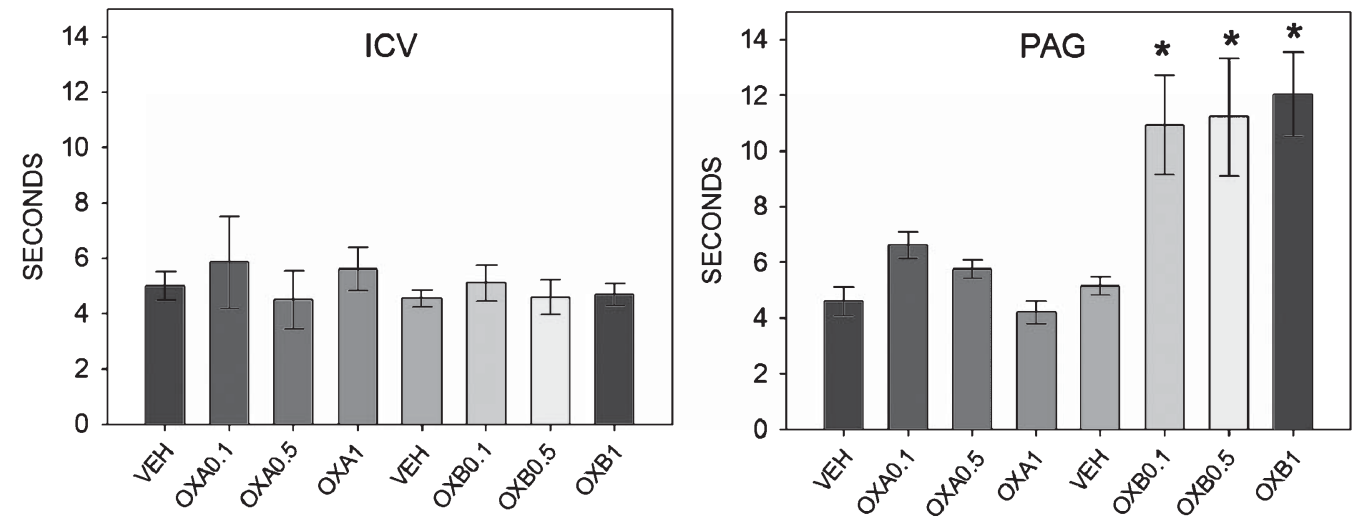

Fig. 4. Mean+SEM of tail-flick latency in seconds in rats microinjected with OX-A, OX-B (0.1, 0.5 and $1 \mathrm{nmol})$ or VEH, ICV or into vl-PAG. All microinjections were in a volume of $1 \mu \mathrm{L} .{ }^{*} P<0.05$ compared to VEH (Student-Newman-Keuls pos-hoc procedure). 
with a key center in vl-PAG, mediated by several neurotransmitters/neuromodulators including significant and negatively both orexins.

In our study OX-A injected ICV dose-dependently decreased duration of CAT, effect achieved with OX-B only at $1 \mathrm{nmol}$. There was no effect of orexins injected in vl-PAG on CAT; showing that vl-PAG is not a center directly related to CAT influenced by orexins at range of $1 \mathrm{nmol}$.

OX-A caused significant decrease in the length of TI with ICV injection only at $1 \mathrm{nmol}$, while OX-B reached this effect at 0.5 and $1 \mathrm{nmol}$, showing more potent effect than OX-A using this route of administration.

ICV injection is expected to affect many brain areas, for the drugs are able to diffuse in the cerebrospinal fluid (CSF) and to reach structures distant from the injection site, while PAG injection would produce high concentrations of the drugs locally that would diffuse in a relative limited area. This may explain in part because both orexins decreased significantly TI duration since the lowest dose tested injected in vl-PAG. In other words, capability of orexins to reduce TI improves when microinjected in vl-PAG. Another possible explanation could be that vl-PAG is the main center in whole CNS for modulation of immobility as defensive response, sensitive to many mediators including orexins. vl-PAG neurons may coordinate a reaction consists of quiescence, hyporeactivity, hypotension, bradycardia and analgesia [23] all these together as part of integrated behavioral defensive response means TI.

On the other hand, in our study no OX-A neither OX-B injected ICV appear activate antinociception using tail-flick test. OX-A $(10 \mathrm{nM}, 5 \mu \mathrm{L})$ injected into the right ventricle failed to elicit significant changes in formalin-induced nociceptive behaviors [24]. However, OX-A was shown to be analgesic when given intravenous (IV) but not subcutaneous (SC) in mouse and rat models with similar efficacy to that of morphine in $50^{\circ} \mathrm{C}$ hot plate test and the carrageenan-induced thermal hyperalgesia test [14]. Intrathecally injection of OX-A, but not OX-B, depressed the phase 1 and phase 2 flinching behavior in the rat formalin test and increased the hot plate latency to hind-paw lick or jump in rats. These effects are mediated by OXR1 in spinal cord [25]. OX-A-induced antinociception in both formalin and hot plate test mainly mediated through OXR1 in paragigantocellularis lateralis nuclei [26]. Other study performed in mice, OX-A and B showed antinociceptive effects in all four types of assays for thermal, mechanical, chemical nociceptions and nociceptin-induced behavioral responses when administered ICV or IT, whereas the SC administration was ineffective [27]. According evidence, orexins participate in antinociception but differences among species, schedule and nociceptive models seem veil their effects. Radiant heat constitutes a relatively selective stimulus for nociceptors and has an advantage over the other models of thermal stimulation in that it produces no tactile stimulus [13]. OX-A had no effect on tail-flick test as thermal and acute pain model injected unilaterally into the PAG (including dorsal, lateral and ventrolateral columns) at the concentrations up to 10 $\mathrm{nM}$ in Sprague Dawley rats [24]. Our results reveal similar effects since the intra-vl-PAG injection of OXA in concentration ranging $0.1-1 \mathrm{nmol}$ did not affect nociception assessed by the tail-flick test.

However, in the present study OX-B elicited important analgesia when microinjected into vl-PAG at 0.1 , 0.5 and $1 \mathrm{nmol}$ in Wistar rats assessed by the tail-flick test. To our knowledge, this is the first study which shows analgesic effect of OX-B injected into vl-PAG. This strongly suggests that OX-B induced-analgesia by activating central mechanisms of the pain control system at level of vl-PAG.

OX-A have equal affinity to OXR1 and OXR2, whereas OX-B has $\sim 10$-fold greater affinity to OXR2 than OXR1 [28]. Analgesic effect of OX-B into vlPAG would mainly be mediated by the OXR2. The mechanism of action of the OX-B in this case seems to be more complex, however, because the OXR2 also binds OX-A with similar affinity, so that a similar acute analgesic effect would be expected for OX-A, which did clearly not happen. A first possible explanation of these results would be that the activity of the OXR1, depending mainly on OX-A, would counteract the analgesic effect of the OXR2. However, data from a previous study [24] show that in PAG OXR1 s mediate the delayed analgesic action of OX-A at range of $0.1-10 \mathrm{nM}$, so that it seems unlikely that they could also blunt the acute analgesia induced by OX-B. Alternatively, our results suggest that OX-B could elicit antinociception by activating some other mechanism besides OXR2-coupled intracellular cascade but associated with this in some way. Such a mechanism could involve the response cascade to other analgesic agents also acting at the PAG, such as NPY [29], which $\mathrm{Y}_{1}$ receptor is coupled to a $\mathrm{G}_{1}$ protein.

In Chinese hamster ovary cells, Holmqvist and coworkers demonstrated that OXR1 couple to at least three different signal pathways to regulate adenylyl cyclase activity: 1) $\mathrm{G}_{\mathrm{i} / 0}$ to inhibit cAMP generation, 2) $\mathrm{G}_{\mathrm{s}}$ to stimulate cAMP generation, and 3) PKC (via PLC and putatively, $\mathrm{G}_{\mathrm{q}}$ ) to stimulate cAMP generation [30]. 
Probably OXR2 also activates many signal pathways. To explain our results, OX-B binding to OXR2 and acting through inhibition of cAMP production seems to be the most likely mechanism of action, which is similarly described to opioids to produce analgesia.

In another in vitro study with vl-PAG slices, orexin A (30-300 nM) depressed GABAergic inhibitory postsynaptic currents. This effect was blocked by an OXR1 antagonist (SB 334867), but not OXR2 antagonist (compound 29). Therefore may produce antinociception by activating postsynaptic OXR1, stimulating synthesis of 2-arachidonoylglycerol, an endocannabinoid through a $\mathrm{G}_{\mathrm{q}}$-protein-mediated 1,2diacylglycerol lipase (PLC-DAGCL $\alpha$ ) enzymatic cascade [31]. Same mechanism of action has been proposed as analgesic to sulfated cholecystokinin in PAG by another in vitro study [32] and via metabotropic glutamate receptor mediated endocannabinoid retrograde disinhibition for capsaicin [33]. However, to our knowledge this action mechanism has not been demonstrated for orexin B yet. The present data are insufficient to explain these results and more studies remain to be conducted.

In summary, our findings point to a complex and differential sensitivity to orexins microinjected either ICV or within the vl-PAG to determine the different traits of cataleptic immobility, tonic immobility, and analgesia. This seems to be related to the actions of the two orexins, different types of orexin receptors at different level of the CNS and especially at PAG. Considering the roles attributed to the orexinergic outputs of the hypothalamus, this suggests that the control of some complex behaviors, such as arousal, food seeking, reward or REM-sleep, involves the modification of the motor control and antinociception by a direct action of the hypothalamic projections on the orexinergic receptors in the midbrain, particularly PAG, besides other well known related nuclei in brainstem.

\section{CONCLUSIONS}

Orexin A and orexin B microinjected ICV or into vl-PAG cause different modulation on two types of immobility response (cataleptic and tonic) and different antinociceptive reaction in rat, being OX-B powerful analgesic agent injected into vl-PAG.

\section{ACKNOWLEDGMENTS}

This work was supported by funds from the Instituto Politécnico Nacional (SAPPI: 20082197). PVL are fellow of Consejo Nacional de Ciencia y Tecnología (330090). We wish to thank to Liz Mariela Martínez Mejía for her collaboration in the beginning of this work.

\section{CONFLICT OF INTEREST STATEMENT}

Authors declare that they have not any conflict of interest with funding sources of this study.

\section{REFERENCES}

[1] Date Y. Ueta Y. Yamashita H. Yamaguchi H. Matsukura S. Kangawa K. Sakurai T. Yanagisawa M. Nakasato M. Orexins, orexinergic hypothalamic peptides, interact with autonomic, neuroendocrine and neuroregulatory systems. Proc Natl Acad Sci USA. 1999; 96: 748-753.

[2] Kastin AJ. Akestrom V. Orexin A but not orexin B rapidly enters brain from blood by simple diffusion. J Pharmacol Exp Ther. 1999; 289: 219-223.

[3] Peyron C, Tighe DK, van den Pol AN, de Lecea L, Heller HC, Sutcliffe JG, Kilduff TS. Neurons containing hypocretin (orexin) project to multiple neuronal systems. J Neurosci. 1998; 18: 9996-10015

[4] Marcus JN, Aschkenasi CJ, Lee CE, Chemelli RM, Saper CB, Yanagisawa M, Elmquist JK. Differential expression of orexin receptors 1 and 2 in the rat brain. J Comp Neurol. 2001; 435: 6-25.

[5] Sakurai T. Orexins and orexin receptors. In: Lecea L, Sutcliffe JG, editors. Hypocretins integrators of physiological signals. La Jolla CA: Springer, 2005, pp. 13-23.

[6] Gallup Jr. GG. Animal hypnosis: Factual status of a fictional concept. Psychol Bull. 1974; 81: 836-853.

[7] Klemm WR. Behavioral arrest: In search of neural control system. Prog Neurobiol. 2001; 65: 453-471.

[8] Baez LA, Eskridge NK, Schein R. Postnatal development of dopaminergic and cholinergic catalepsy in the rat. Eur $\mathrm{J}$ Pharmacol. 1976; 36: 155-162.

[9] Ramos CM, Souza SLF, Menescal OL. Modulation of tonic immobility in guinea pig PAG by homocysteic acid, a glutamate agonist. Physiol Behav. 2008; 94: 468-473.

[10] Rodgers RJ, Ishii Y, Halford JCG, Blundell JE. Orexins and appetite regulation. Neuropepetides. 2002; 36(5): 303-325.

[11] Morgan MM, Whitney PK, Gold MS. Immobility and flight associated with antonociception produced by activation of the ventral and lateral/dorsal regions of the rat periaqueductal gray. 1998; 804: 159-166.

[12] Bandler R, Depaulis A. Midbrain periaqueductal gray control of defensive behavior in the cat and in the rat. In: A. Depaulis and R. Bandler (Eds.), The midbrain periaqueductal gray matter: Functional, Anatomical and Neurochemical Organization. Plenum Press, New York, 1991, pp. 175-198.

[13] Le Bars D, Gozariu M, Cadden SW. Animal models of nociception. Pharmacol Rev. 2001; 53: 597-652.

[14] Bingham S, Davey PT, Babbs AJ, Irving EA, Sammons MJ, Wyles M, Jeffrey P, Cutler L, Riba I, Johns A, Porter RA, Upton N, Hunter AJ, Parsons AA. Orexin-A an hypothalamic peptide with analgesic properties. Pain. 2001; 92: 81-90.

[15] Xie W, Wisor JP, Hara J, Crowder TL, LeWinter R, Khroyan TV, Yamanaka A, Diano S, Horvath TL, Sakurai T, Toll L, Kilduff TS. Hypocretin/orexin and nociceptin/orphanin FQ 
coordinately regulate analgesia in a mouse model of stressinduced analgesia. J Clin Inv. 2008; 118(7): 2471-2481.

[16] Paxinos G, Watson C. The rat brain in stereotaxic coordinates. Academic Press. Inc. New York. 1986.

[17] Fregoso ATA, Zamudio SR. Differential effect of testosterone and repetitive induction on cataleptic and dorsal immobility in mice. Horm Behav. 2006; 50: 27-32.

[18] Sandoval HV, Trujillo FJG, Miranda PA, De la Cruz F, Zamudio SR. Corticosterone microinjected into nucleus pontis oralis increases tonic immobility in rats. Horm Behav. 2011; 60: $448-456$.

[19] Overeem S, Lammers GJ, van Dijk G. Cataplexy: 'Tonic immobility' rather than 'REM-sleep atonia'? Sleep Med. 2002; 3: 471-477.

[20] Chemelli RM, Willie JT, Sinton CM, Elmquist JK, Scamell T, Lee C, Richardson JA, Williams SC, Xiong Y, Kisanuki Y, Fitch TE, Nakazato M, Hammer RE, Saper CB, Yanagisawa M. Narcolepsy in orexin knockout mice: Molecular genetics of sleep regulation. Cell. 1999; 98: 437-451.

[21] Horvath T, Peyron C, Diano S, Ivanov A, Aston-Jones G, Kilduff T, van den Pol A. Hypocretin (orexin) activation and synaptic innervation of the locus coeruleus noradrenergic system. J Comp Neurol. 1999; 415: 145-159.

[22] Kiyashchenko LI, Mileykovskiy BY, Lai YY, Siegel JM. Increased and decreased muscle tone with orexin (hypocretin) microinjection in the locus coeruleus and pontine inhibitory area. J Neurophys. 2001; 85: 2008-2016.

[23] Depaulis A, Keay K, Bandler R. Quiescence and hyporeactivity evoked by activation of cell bodies in the ventrolateral midbrain periaqueductal gray in rat. Exp Brain Res. 1994; 99: 75-83.

[24] Zarmehri HA, Semnanian S, Fathollahi Y, Erami E, Khakpay R, Azizi H, Rohampour K. Intra-periaqueductal gray matter microinjection of orexin-A decreases formalin-induced nociceptive behaviors in adult male rats. J Pain. 2011; 12: 280-287.

[25] Yamamoto T, Nozaki TN, Chiba T. Analgesic effect of intrathecally administered orexin-A in the rat formalin test and in the rat hot plate test. Br J Pharmacol. 2002; 137: 170-176.
[26] Erami E, Azhdari ZH, Ghasemi DE, Mohammad HE, Semnanian S. Intra-paragigantocellularis lateralis injection of orexin-A has an antinociceptive effect on hot plate and formalin tests in rat. Brain Res. 2012; 1478: 16-23.

[27] Mobarakeh JI, Takahashi K, Sakurada S, Nishino S, Watanabe H, Kato M, Yanai K. Enhanced antinociception by intracerebroventricularly and intrathecally-administered orexin A and B (hypocretin-1 and -2) in mice. Peptides. 2005; 26: 767-777.

[28] Sakurai T, Amemiya A, Ishii M, Matsuzaki I, Chemelli RM, Tanaka, Williams SC, Richardson JA, Kozlowski GP, Wilson S, Arch JR, Buckingham RE, Haynes AC, Carr SA, Annan RS, McNulty DE, Liu WS, Terret JA, Elshourbagy NA, Bergsma DJ, Yanagisawa M. Orexins and orexin receptors: A family of hypothalamic neuropeptides and $\mathrm{G}$ protein-coupled receptors that regulate feeding behavior. Cell. 1998; 92(4): 573-585.

[29] Wang JZ, Lundeberg T, Long CY. Antinociceptive effects induced by intra-periaqueductal grey administration of neuropeptide $\mathrm{Y}$ in rats. Brain Res. 2000; 859: 361-363.

[30] Holmqvist T, Johansson L, Östman M, Ammoun S, Akerman KEO, Kukkonen JP. OX $\mathrm{OX}_{1}$ orexin receptors couple to adenylyl cyclase regulation via multiple mechanisms. J Biol Chem. 2005; 280(8): 6570-6579.

[31] Ho YC, Lee HJ, Tung LW, Liao YY, Fu SY, Teng SF, Liao HT, Mackie K, Chiou LC. Activation of orexin 1 receptors in the periaqueductal gray of male rats leads to antinociception via retrograde endocannabinoid (2-arachidonoylglycerol)-induced disinhibition. J Neurosci. 2011; 31(41): 14600-14610.

[32] Mitchell VA, Jeong HJ, Drew GM, Vaughan CW. Cholecystokinin exerts an effect via the endocannabinoid system to inhibit GABAergic transmission in midbrain periaqueductal gray. Neuropsychophar. 2011; 36: 1801-1810.

[33] Liao HT, Lee HJ, Ho YC, Chiou LC. Capsaicin in the periaqueductal gray induces analgesia via metabotropic glutamate receptor mediated endocannabinoid retrograde disinhibition. Br J Pharmacol. 2011; 163: 330-345. 